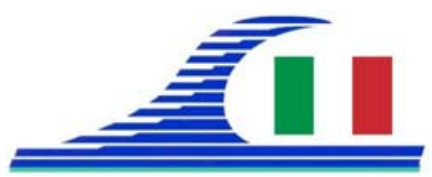

Conférence Méditerranéenne Côtière et Maritime EDITION 3, FERRARA, ITALIA (2015)

Coastal and Maritime Mediterranean Conference

Disponible en ligne - http://www.paralia.fr - Available online

\title{
Wave-bottom-current interaction in the presence of a 3D bathymetry: effects on the vertical sheared current and enhancement of transverse wave modes
}

\author{
Vincent REY $^{1,2}$, Julien TOUBOUL ${ }^{1,2}$
}

1. Université de Toulon, CNRS/INSU, IRD, Mediterranean Institute of Oceanography (MIO), UM 110, 83957 La Garde, France.

2. Aix Marseille Université, CNRS/INSU, IRD, Mediterranean Institute of Oceanography

(MIO), UM 110, 13288 Marseille, France.rey@univ-tln.fr; touboul@univ-tln.fr

\begin{abstract}
:
Experiments were carried out in the Ocean Engineering Basin (BGO) FIRST, France, of useful length 24 metres and effective width 16 metres. A tridimensional bathymetry consisting of two symmetrical submerged mounds of maximum extension $8.5 \mathrm{~m}$ lengthwise was displayed on the flat bed on both sides of the basin. The maximum water depth was of $3 \mathrm{~m}$, the water depth above the top of the mounds was of $1.5 \mathrm{~m}$. Regular waves of period $\mathrm{T}=2.40 \mathrm{~s}$, corresponding to finite water depth above the bathymetry were generated in opposing current conditions. For the tests of current only, acceleration is observed in the upper layer above the mound over the whole basin width. A decrease of the near surface current intensity is observed downstream due to a vertical mixing. For the two wave amplitude conditions experimented, the vertical mixing is enhanced in the presence of the waves. Concerning the wave field, a strong tridimensional behaviour is observed for the amplitude. Transversal modes are found to be excited by the current due to the geometry of the basin.
\end{abstract}

Keywords: Wave-current interactions, Large scale experiments, Vertical mixing, Transverse modes.

\section{Introduction}

During the last decades, a huge effort has been made for a better understanding and modelling of water wave propagation in the presence of currents. In the purpose of the maritime navigation, local increase of wave steepness may become dramatic when huge waves are generated. For coastal engineering purposes, currents may affect the wave conditions at the shore, in addition to the bathymetric effects.

Vertically sheared currents, often observed in the field, may also have a significant impact on the wave phase evolution during propagation. Indeed, analytical models demonstrate an influence of the vertical shear value on the wave celerity and on the water particles kinematics (SWAN \& JAMES, 2001). Since wave celerity depends on the current vertical shear intensity, one may thus expect further effects on the wave 
Côtes méditerranéennes menacées :

Risques et défis dans le contexte du changement climatique

propagation in addition to the classical bathymetric and/or depth integrated current effects in 3D cases.

Quantitative experimental studies of three-dimensional wave-current interactions remain rare. The present experiments were carried out in the large scale ocean basin BGO FIRST (La Seyne/Mer, France), designed for the study of wave structure or wavebottom interactions in the presence of currents (MAGNE et al., 2005; REY \& TOUBOUL, 2011). A tridimensional bathymetry consisting of two symmetrical submerged mounds of maximum extension $8.5 \mathrm{~m}$ lengthwise was displayed on the flat bed on both sides of the basin. The generated mean current is then three-dimensional. In a first set of experiments, deep water wave conditions were considered. In these conditions, a wave focusing in the central part of the basin has been observed. The coupled effect between the wave and the mean current shield was also discussed (REY et al., 2014).

The aim of the present work is the study of the wave-current interactions in waveopposing current conditions in terms of vertical sheared current effects and enhancement of transverse oscillating modes in finite depth conditions. In section 2, the wave basin, the experimental set-up and the instrumentation are presented. Results for both the mean field and the wave induced hydrodynamics in the presence of current are reported in section 3 and discussed.

\section{Experimental set-up}

The Ocean Engineering Basin (BGO) FIRST has a useful length of $24 \mathrm{~m}$, an effective width of $16 \mathrm{~m}$. The BGO is equipped with a current generator, a wave-maker over the entire width and a XY carriage working in a Cartesian coordinate system. The X-axis corresponds to the incoming wave direction, the $\mathrm{Y}$-axis to the cross direction, and the Zaxis is vertical upwards. A permeable wave absorber with parabolic shape is located at the end of the tank.

Hydrodynamics data were obtained thanks to wave gauges (WG), pressure sensors (PS) and an electromagnetic current meter (CM). Pressure sensors PS1 to PS11 had a fixed position. WG, PS11 to PS18 and the CM were displayed on the moving carriage. Measurements were carried out for the following positions of the carriage along the $\mathrm{X}$ axis, $X_{n}=-8,-6.05,-4.1,-2.8,0,2.8,4.1,6.05$ and 8m. In addition, the CM could be positioned along Y-axis at the following positions (1 to 4), $\mathrm{Y}_{\mathrm{n}}=-0.53,-2.23,-3.93$ and $5.58 \mathrm{~m}$. The positions of the instruments are presented in Tab. 1.for the carriage position $\mathrm{X}_{\mathrm{c}}=0$.

The wave were regular, of period $\mathrm{T}=2.40 \mathrm{~s}$. Two amplitude conditions, $\mathrm{H}=0.10$ and 0.20 $\mathrm{m}$ for the incident wave were generated. The opposing current intensity was $\mathrm{U}=-0.25 \mathrm{~m} / \mathrm{s}$. The ratio $\mathrm{h} / \lambda=0.4$ for $\mathrm{h}=3 \mathrm{~m}$ that corresponded to finite depth conditions. 


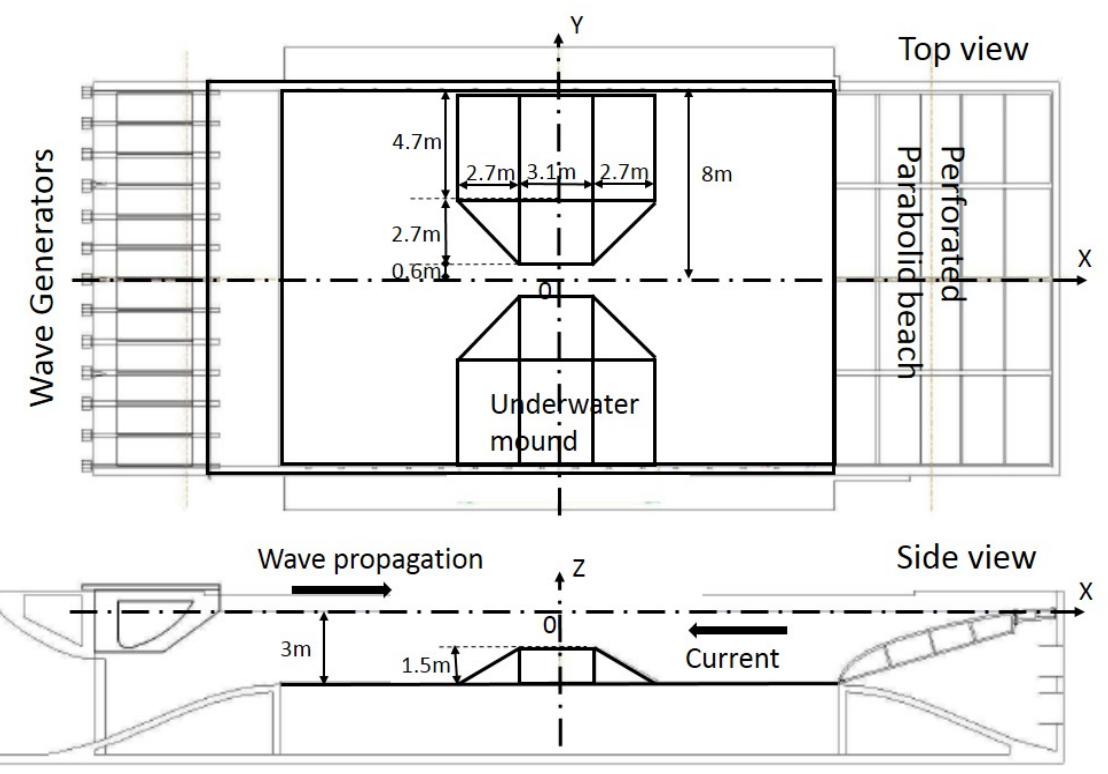

Figure 1. Sketch of the experiments.

\section{Results and discussions}

\subsection{Mean current}

Mean velocities are given by the $\mathrm{CM}$ at $\mathrm{Z}=-0.25 \mathrm{~m}$. Results are presented in Fig. 2 for the current alone and for wave opposing current conditions $(\mathrm{H}=10 \mathrm{~cm}$ and $\mathrm{H}=20 \mathrm{~cm})$ along the $\mathrm{X}$-axis for cross sections $\mathrm{Y}=0.53,-2.23,-3.93$ and -5.58 . For both tests, acceleration is observed in the upper layer above the mound over the whole basin width. A decrease of the near surface current intensity is observed downstream due to mixing. For the two wave amplitude conditions experimented, the decrease of the near-surface flow is enhanced downstream (up-wave) the mound on the whole cross-section, demonstrating a higher vertical mixing in the presence of the waves.

\subsection{Wave amplitude}

The surface wave field can be obtained directly from wave gauges or from either pressure sensors or current meter through a transfer function which assumes a progressive linear plane wave and no vertically sheared current (see Rey et al, 2014). Elevations relative to the incident wave at $(X, Y)=(0,0)$ are presented versus $X$-axis in Fig. 3 at four given cross-sections. Comparisons are made with an elliptic refractiondiffraction model assuming uniform mean velocity fields along the vertical axis (REY et al., 2014). The calculations are made for the mean current field measured in the absence of waves. As shown in Fig. 3, we can first observe that the relative free surface field does not depend significantly on the wave amplitude (conditions $\mathrm{H}=10 \mathrm{~cm}$ and $\mathrm{H}=20 \mathrm{~cm}$ ). A strong wave amplification up wave and down wave the mound location 
Côtes méditerranéennes menacées :

Risques et défis dans le contexte du changement climatique

with respect to the incoming wave $(\mathrm{X}=-8 \mathrm{~m})$ is observed in the central axis $\mathrm{X}(\mathrm{Y}=0)$ and at the top of the transverse slope of the mounds $(X=0, Y=3.5)$. Small amplitude oscillations are observed in the middle of the basin $(X=Y=0)$. Some significant differences are observed for the free surface deformations given either by the WG or by the other instruments. Reflection from the mounds, calculated with a two gauges method, was found to remain weak. Discrepancies between the direct measurement of the surface elevation and the calculations through transfer functions tend to demonstrate that vertical sheared effects are not negligible. The oscillating behavior seems to be due to nearly resonant conditions for the transverse modes, since the wave wavelength, of about $7.46 \mathrm{~m}$ for $\mathrm{h}=3 \mathrm{~m}$, is near half the basin width.

Numerical results are found to reproduce correctly the wave shape in the central part of the basin, some further calculations including the mean current for the considered wave conditions are in progress to help to understand the discrepancy observed.

Table. 1. Location of the instruments. PS1 to PS11 are at fixed positions. Positions of WG, PS 12 to 18 and CM along X axis vary with the location of the carriage. Locations given in the table correspond to the carriage location $X_{c}=0$. Vertical position for pressure sensors $P 12$ to $P 18$ is $Z=-0.75 m$.

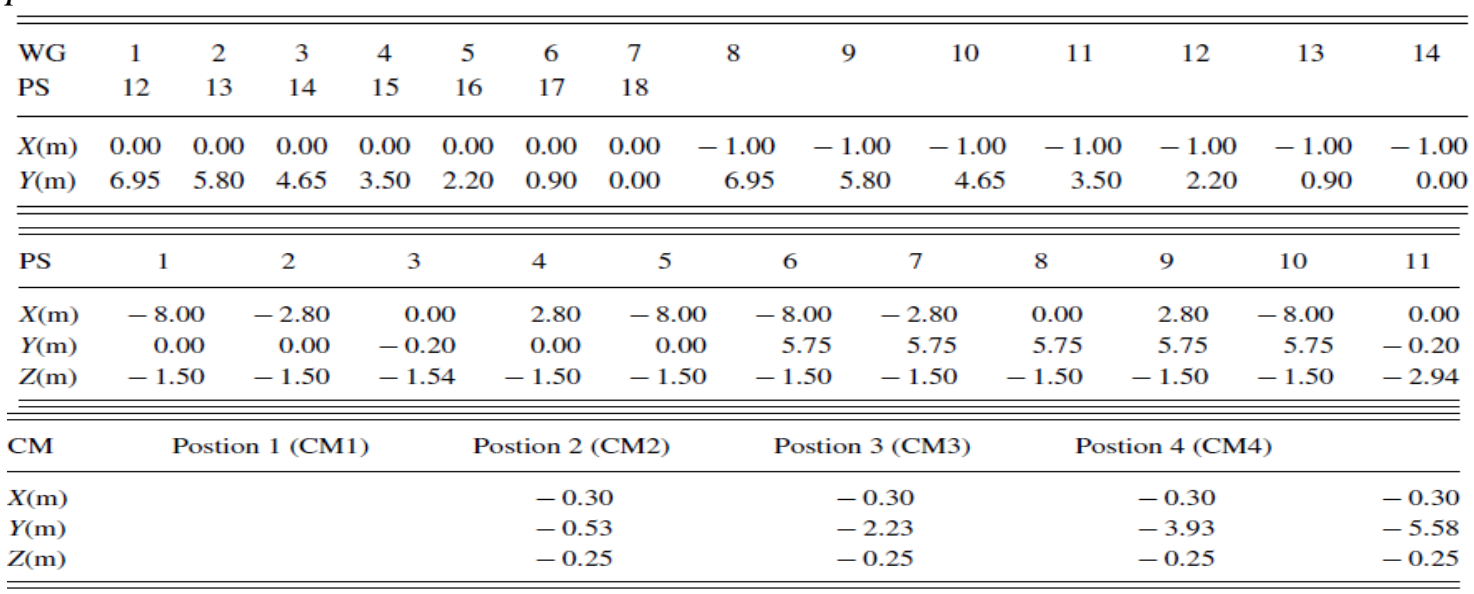




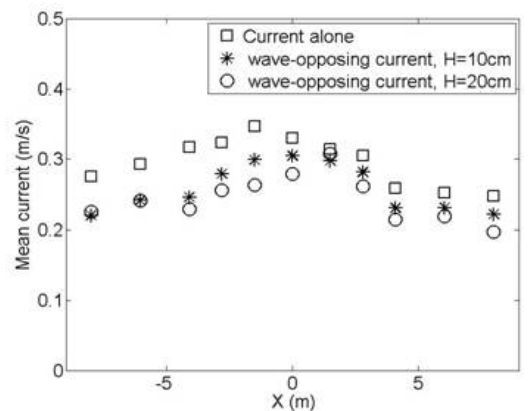

(a) $Y=-0.53, Z=-0.25$

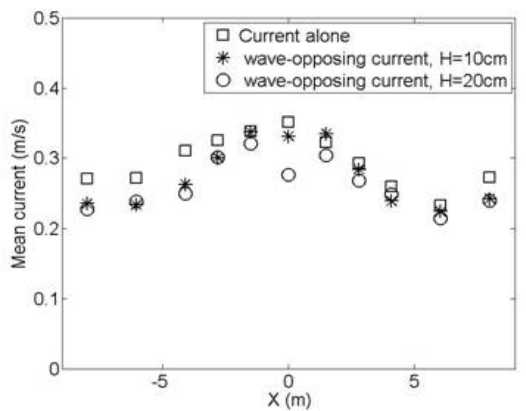

(c) $Y=-3.93, Z=-0.25$

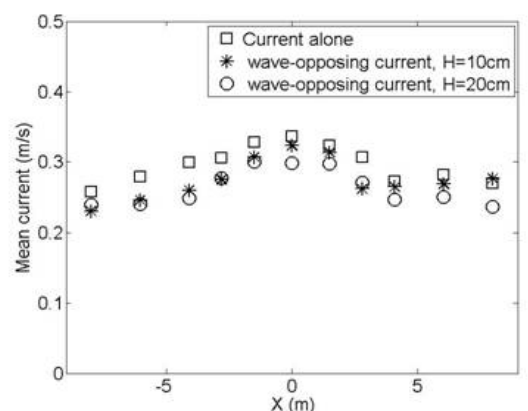

(b) $Y=-2.23, Z=-0.25$

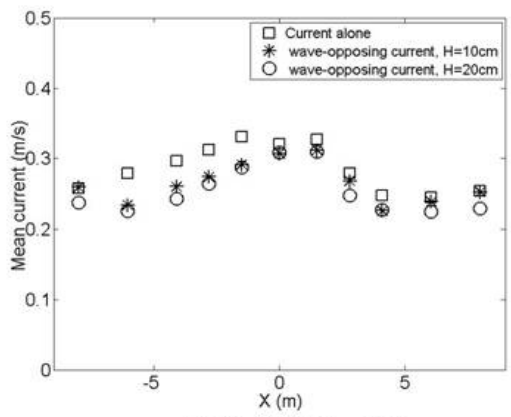

(d) $Y=-5.58, Z=-0.25$

Figure 2. Mean velocity for various locations.

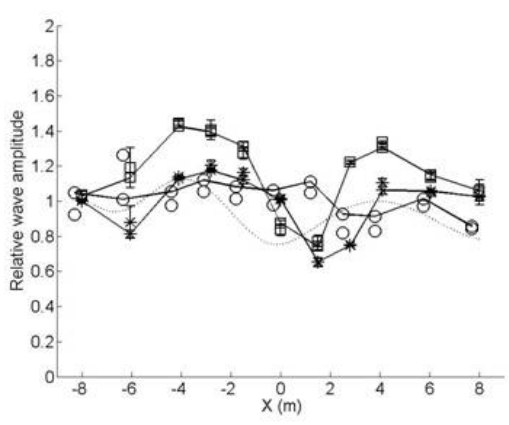

(a) $Y=0$ (WG, PS), $Y=-0.53$ (CM)

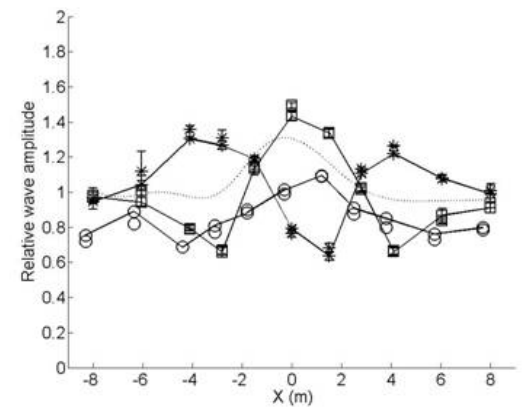

(c) $Y=3.5(W G, P S), Y=-3.93(\mathrm{CM})$

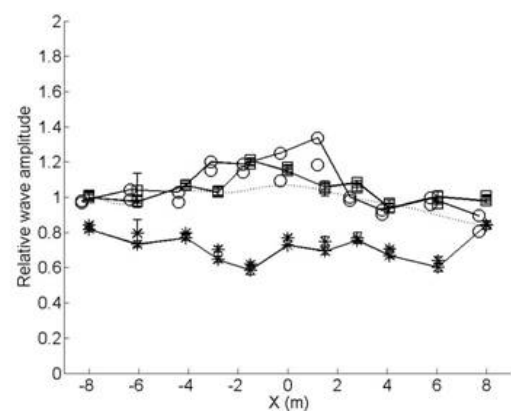

(b) $Y=2.2(W G, P S), Y=-2.23(\mathrm{CM})$

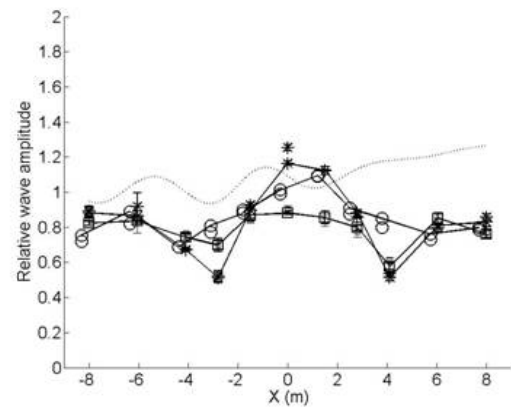

(d) $Y=5.8(W G, P S), Y=-5.58(\mathrm{CM})$

Figure 3. Surface deformation at the wave frequency at various locations (...) model, $H=10 \mathrm{~cm}$, full line and symbols, $H=20 \mathrm{~cm}$, symbols : $\left(^{*}\right) W G$, ( $\left.\square\right) P S,(o) C M$. 
Côtes méditerranéennes menacées :

Risques et défis dans le contexte du changement climatique

\section{Acknowledgements:}

This work was supported by ANR grant $N^{\circ}$ ANR-13-ASTR-0007.

\section{References}

MAGNE R., REY V., ARDHUIN F. (2005). Measurement of wave scattering by topography in presence of current. Phys. Fluids, Vol. 17, 126601. http://dx.doi.org/10.1063/1.2140283

REY V., CHARLAND J., TOUBOUL J. (2014). Wave-current interaction in the presence of a three-dimensional bathymetry: Deep water wave focusing in opposing current conditions. Phys. Fluids, Vol. 26, 096601. http://dx.doi.org/10.1063/1.4894740

REY V., TOUBOUL J. (2011). Forces and moment on a horizontal plate due to regular and irregular waves in the presence of current. Applied Ocean Res., Vol. 33, pp 88-99. http://dx.doi.org/10.1016/j.apor.2011.02.002

SWAN C., JAMES R. L. (2001). A simple analytical model for surface water waves on a depth-varying current. Applied Ocean Res., Vol. 22, pp 331-347. http://dx.doi.org/10.1016/S0141-1187(00)00022-5 